УДК 519.711

Борис Леонідович Бутвін (доктор технічних наук, професор)

Олександр Олександрович Машкін (кандидат технічних наук, с.н.с.)

Олексій Іванович Соломицький (кандидат технічних наук, с.н.с.)

Центральний науково-дослідний інститут Збройних Сил Украйни, Киӥв, Украйна

\title{
МЕТОД РОЗРАХУНКУ ІНТЕГРАЛЬНОГО ПОКАЗНИКА ЯКОСТІ МОДЕЛЕЙ ТА ПОЛІМОДЕЛЬНИХ КОМПЛЕКСІВ ОПЕРАЦІЙ (БОЙОВИХ ДІЙ)
}

У статті розглядаються особливості оиінювання якості моделей та полімодельних комплексів операчій (бойових дій). Такі моделі є дієвим та необхідним інструментом проведення оперативних розрахунків на заходах оперативної підготовки, а прочедура оцінки їх якісних властивостей - важливим та відповідальним етапом життевого цииклу. В рамках теоретичної кваліметрії розрізняють прямі та зворотні задачі оцінювання якості, в основі першої лежить безпосереднє вимірювання якості, в основі другої задачі - управління якістю продукиії з метою придання йому необхідних властивостей. Особливої актуальності зворотна задача набуває для полімодельних комплексів операчій (бойових дій), які визначально будуються з гнучкою структурою, щяо передбачає можливість включення до їх складу нових моделей або модифікації вже існуючих. Оскільки поняття якості включає як об'єктивні властивості, так $і$ суб'єктивні оцінки корисності об'єкту, які кваліметричними методами оцінюються одним узагальненим показником, природнім $\epsilon$ залучення до таких оиінок експертів у предметній сфері. Розвиненість апарату оброблення експертної інформаиії поряд з сучасними програмними засобами аналізу та оброблення даних надає можливість упорядкування процесу очінювання якості найважливіших властивостей моделей та полімодельних комплексів. Це можливо шляхом встановлення нелінійної аналітичної залежності, яка пов'язує незалежні змінні (оброблені оцінки експертів) $з$ залежною змінною, в ролі якої виступає інтегральна оичінка якості моделей. Приклад побудови такої залежності з високим коефіцієнтом детермінації інтегральної оцінки якості, розглянутий у статті, підтвердив дочільність такого підходу. Наявність зазначеного інструменту оцінювання якості дозволить з достатньо високою точністю розраховувати інтегральний показник якості обраних властивостей моделей, а також може бути використана для кваліметричного аналізу можливих модифікаџій та структурних змін у моделях та полімодельних комплексах операцій (бойових дій).

Ключові слова: кваліметрія моделей; полімодельний комплекс операцій; якісна оцінка властивостей.

\section{Вступ}

Моделі та полімодельні комплекси (ПмК) операцій (бойових дій) є дієвим та необхідним інструментом роботи органів військового управління та оперативних штабів. Оцінка якісних характеристик моделей та ПмК - важливий та відповідальний етап їх життєвого циклу, який завершує, як правило, період дослідної експлуатації моделей. За результатами такої оцінки можна зробити висновок про ступінь придатності моделей до використання за призначенням, або виявити такі їх сторони, що потребують уваги та доопрацювання.

Взагалі, чисельна оцінка та управління якістю будь-якої продукції є основою кваліметрії - науки про вимірювання та кількісну оцінку якості об'єктів та процесів. Якість, як ключове поняття кваліметрії, по відношенню до моделей та ПмК може бути визначена як «властивість або сукупність властивостей моделей, що обумовлюють їх придатність до використання за призначенням» [1]. Важливими для уваги $\epsilon$ декілька аспектів теоретичної кваліметрії, які безпосередньо стосуються моделей та ПмК операцій (бойових дій). Першим таким аспектом слід вважати те, що в рамках кваліметрії розрізняють прямі та зворотні задачі, під якими розуміються відповідно задачі аналізу якості продукції та задачі синтезу заданих (потрібних) їх властивостей. В основі вирішення прямої задачі лежить безпосереднє вимірювання якості, в основі зворотної - управління якістю продукту з метою придання йому необхідних властивостей. Особливої актуальності зворотна задача набуває для ПмК операцій (бойових дій), які визначально будуються 3 гнучкою структурою, що передбачає можливість включення до їх складу нових моделей або модифікації вже існуючих. Так, досвід експлуатації діючого зразка ПмК операцій на 
заходах оперативної підготовки останніх років вказує на те, що модифікація та удосконалення комплексу проводиться достатньо регулярно, це вимагає такої ж постійної уваги до аналізу та управління його якісними характеристиками. Другим важливим аспектом можна вважати включення в поняття якості як об'єктивних властивостей, так і суб'єктивних оцінок корисності об'єкту, які кваліметричними методами оцінюються одним узагальненим показником [2]. Це природнім чином потребує участі експертів (фахівців у предметній області та безпосередніх користувачів моделей) для надання оцінок, насамперед, тим показникам якості, які проблематично описати однозначною чисельною мірою. Наприклад, оцінки таких важливих властивостей як адекватність або адаптивність моделей відображаються, як правило, у інтервальних шкалах, що потребує відповідного їх упорядкування та нормування для подальшої обробки. Методи обробки експертної інформації достатньо розвинені та представлені у тематичній літературі, крім цього, сучасні програмні засоби аналітичної обробки даних надають можливість створювати адекватні моделі 3 високим коефіцієнтом детермінації залежних змінних, в якості яких й можуть бути представлені інтегральні показники якості. Такий аналітичний інструмент здатен значно спростити оцінку якісних характеристик об'єктів, що постійно розвиваються, тобто отримують нові властивості, які і потребують аналізу. До таких об'єктів, безумовно, повною мірою відносяться і згадані вище моделі та ПмК операцій (бойових дій).

Постановка проблеми. Активний розвиток та постійне удосконалення моделей та ПмК операцій (бойових дій) обумовлюють необхідність розгляду питань, пов'язаних 3 автоматизацією всебічного аналізу та оцінювання нових властивостей, набутих моделями в результаті такого розвитку. Раціональним шляхом для цього представляється поєднання розвиненого апарату оброблення експертної інформації з можливостями сучасних засобів аналізу даних. Результатом такого поєднання може бути модель, що встановлює однозначний аналітичний зв'язок між незалежними змінними (оцінками експертів ключових властивостей моделей) та залежною змінною - інтегральною оцінкою якості моделі (ПмК). Крім цього, така модель повинна дозволяти оцінювати внесок кожної з обраних для аналізу властивостей моделі в інтегральний показник якості, а програмний засіб як середовище побудови такої моделі - проводити всі необхідні для аналізу даних перевірки (перевірки залишків на гетероскедастичність, відсутність колінеарних незалежних змінних або кореляції між ними тощо). Власне, дослідження за побудованою таким чином моделлю будуть певним чином вирішувати дві типові задачі кваліметрії - проводити чисельну оцінку якості вже розроблених програмних продуктів, а також аналізувати зміни, які відбудуться у інтегральній оцінці їх якості при модифікації або структурних змінах для прийняття обгрунтованого рішення про доцільність або корисність таких змін.

Аналіз останніх досліджень і публікацій. Серед робіт, присвячених розгляду питань за тематикою статті, можна виділити: у теоретичному плані - монографію [1] та публікації $[3,4]$; у прикладному - практичне керівництво [5]. В рамках робіт $[1,3,4]$ їх авторами декларується думка про те, що розвиток теорії кваліметрії моделей неможливий без узагальнення результатів досліджень, що проводяться відносно якісних властивостей спеціалізованих моделей (ПмК) у суто прикладних сферах досліджень. Погоджуючись 3 цією думкою авторів, можна вважати, що реалізація ключових теоретичних положень кваліметрії у практичній площині відносно достатньо спеціалізованих моделей операцій (бойових дій) $є$ актуальним прикладним завданням, розгляд питань розробки моделі оцінювання якості полімодельного комплексу операцій і становить мету статті.

\section{Виклад основного матеріалу дослідження}

Постановочна частина задачі побудови моделі оцінювання якісних властивостей ПмК операцій (бойових дій) може бути сформульована наступним чином. Існує полімодельний комплекс (який являє собою сукупність аналітичних та імітаційних моделей операцій, а також ряду інформаційно-розрахункових задач, що використовують єдину базу даних та геоінформаційну систему), який активно застосовується на більшості заходів оперативної підготовки 3 органами військового управління оперативного та оперативно-стратегічного рівнів. Експертам, якими визначені фахівці з оперативної підготовки відповідного рівня та особи, безпосередньо відповідальні за експлуатацію комплексу в процесі навчань та тренувань, було запропоновано: по-перше, обрати п’ять найважливіших властивостей, що вирішальним чином впливають на узагальнену оцінку якості ПмК операцій; по-друге, оцінити якість обраних властивостей за інтервальною шкалою [0;1]. У відповідності до рекомендацій [6] щодо планування експерименту для п'яти параметрів в якості вихідних даних для подальших обчислень необхідно сформувати таблиці розмірності 5 (обраних властивостей) на 21 (експертних оцінок). Залишаючи поза розглядом методичні деталі процедур експертного оцінювання, зауважимо лише, що вибір результуючої таблиці здійснювався за типовим алгоритмом пошуку медіани Кемені.

У підсумку роботи експертів у такій постановці отримуємо набір упорядкованих та віднормованих значень, які можна обробляти 3 урахуванням основних положень аналізу даних, викладених, наприклад, у [5]. Серед достатньо повного 
переліку типових властивостей моделей та полімодельних комплексів, розглянутих у $[1,3,4]$, експертами визначені як найважливіші: адекватність; адаптивність; стійкість (у роботі); простота (з точки зору користувача); достовірність результатів. В якості програмного пакету для проведення аналізу та оброблення отриманих даних доцільно обрати такий, в якому реалізуються алгоритми нейроних мереж, а базова модель пов'язує залежну змінну у (інтегральну оцінку якості) 3 незалежними змінними $\mathrm{x}$ (оціночними судженнями експертів відносно якості властивостей ПмК) за допомогою поліному Колмогорова - Габора виду:

$$
\begin{aligned}
\mathrm{y}= & \omega_{0}+\sum_{\mathrm{i}=1}^{\mathrm{m}} \omega_{\mathrm{i}} \mathrm{x}_{\mathrm{i}}+\sum_{\mathrm{i}=1}^{\mathrm{m}} \sum_{\mathrm{j}=1}^{\mathrm{m}} \omega_{\mathrm{ij}} \mathrm{x}_{\mathrm{i}} \mathrm{x}_{\mathrm{j}}+ \\
& +\sum_{\mathrm{i}=1}^{\mathrm{m}} \sum_{\mathrm{j}=1}^{\mathrm{m}} \sum_{\mathrm{k}=1}^{\mathrm{m}} \omega_{\mathrm{ijk}} \mathrm{x}_{\mathrm{i}} \mathrm{x}_{\mathrm{j}} \mathrm{x}_{\mathrm{k}}+\ldots
\end{aligned}
$$

У такій моделі $\mathrm{x}=\left\{\mathrm{x}_{\mathrm{i}} \mid \mathrm{i}=1, \ldots, \mathrm{m}\right\}$ - множина незалежних змінних, а $\omega$ - вектор параметрів вагових коефіцієнтів:

$$
\omega=\left\langle\omega_{\mathrm{i}}, \omega_{\mathrm{ij}}, \omega_{\mathrm{ijk}}, . . \mid \mathrm{i}, \mathrm{j}, \mathrm{k}, \ldots=1, \ldots, \mathrm{m}\right\rangle .
$$

Основні особливості побудованої таким чином моделі оцінювання якості властивостей ПмК можуть бути пояснені за допомогою матеріалу, який представлений на наступних рисунках.

На рис.1 - вихідні дані у вигляді нормованих оцінок експертів по кожній 3 обраних властивостей. На рис. 1 прийняті наступні позначення: $\alpha 1$ - адекватність; $\alpha 2$ - адаптивність; $\alpha 3$ - стійкість у роботі; $\alpha 4$ - простота користування; $\alpha 5$ - достовірність результатів.

\begin{tabular}{lllllll} 
Ekcn. & a1 & a2 & a3 & a4 & a5 & as/5 \\
\hline 1 & 0,67 & 0,72 & 0,8 & 0,71 & 0,64 & 0,708 \\
\hline 2 & 0,71 & 0,67 & 0,67 & 0,81 & 0,73 & 0,718 \\
\hline 3 & 0,59 & 0,8 & 0,79 & 0,85 & 0,74 & 0,754 \\
\hline 4 & 0,64 & 0,79 & 0,73 & 0,75 & 0,65 & 0,712 \\
\hline 5 & 0,75 & 0,71 & 0,7 & 0,85 & 0,58 & 0,718 \\
\hline 6 & 0,8 & 0,57 & 0,85 & 0,87 & 0,72 & 0,762 \\
\hline 7 & 0,69 & 0,75 & 0,8 & 0,75 & 0,68 & 0,734 \\
\hline 8 & 0,73 & 0,69 & 0,77 & 0,77 & 0,7 & 0,732 \\
\hline 9 & 0,81 & 0,77 & 0,81 & 0,85 & 0,68 & 0,784 \\
\hline 10 & 0,58 & 0,6 & 0,65 & 0,77 & 0,65 & 0,65 \\
\hline 11 & 0,66 & 0,67 & 0,78 & 0,88 & 0,7 & 0,738 \\
\hline 12 & 0,69 & 0,81 & 0,74 & 0,91 & 0,55 & 0,74 \\
\hline 13 & 0,65 & 0,77 & 0,79 & 0,79 & 0,72 & 0,744 \\
\hline 14 & 0,69 & 0,81 & 0,85 & 0,85 & 0,71 & 0,782 \\
\hline 15 & 0,7 & 0,8 & 0,83 & 0,79 & 0,64 & 0,752 \\
\hline 16 & 0,65 & 0,65 & 0,9 & 0,9 & 0,75 & 0,77 \\
\hline 17 & 0,71 & 0,75 & 0,79 & 0,87 & 0,7 & 0,764 \\
\hline 18 & 0,67 & 0,69 & 0,77 & 0,79 & 0,65 & 0,714 \\
\hline 19 & 0,71 & 0,79 & 0,85 & 0,85 & 0,59 & 0,758 \\
\hline 20 & 0,8 & 0,85 & 0,84 & 0,75 & 0,67 & 0,782 \\
\hline 21 & 0,65 & 0,69 & 0,75 & 0,82 & 0,68 & 0,718 \\
\hline
\end{tabular}

Рис. 1. Нормовані експертні оцінки обраних властивостей ПмК

На рис. 2 - результати аналізу гетероскедастичності залишків побудованої моделі. 3 рис. 2 можна зробити однозначний висновок про гомоскедастичність (однорідну варіативність випадкових відхилень) залишків, що свідчить на користь отриманої моделі.

На рис. 3 - результати аналізу автокореляції залишків моделі, які свідчать про те, що залишки некорельовані (висновок за графічним методом рядів, залишки мають асимптотично нормальний розподіл), специфікація моделі обрана правильно

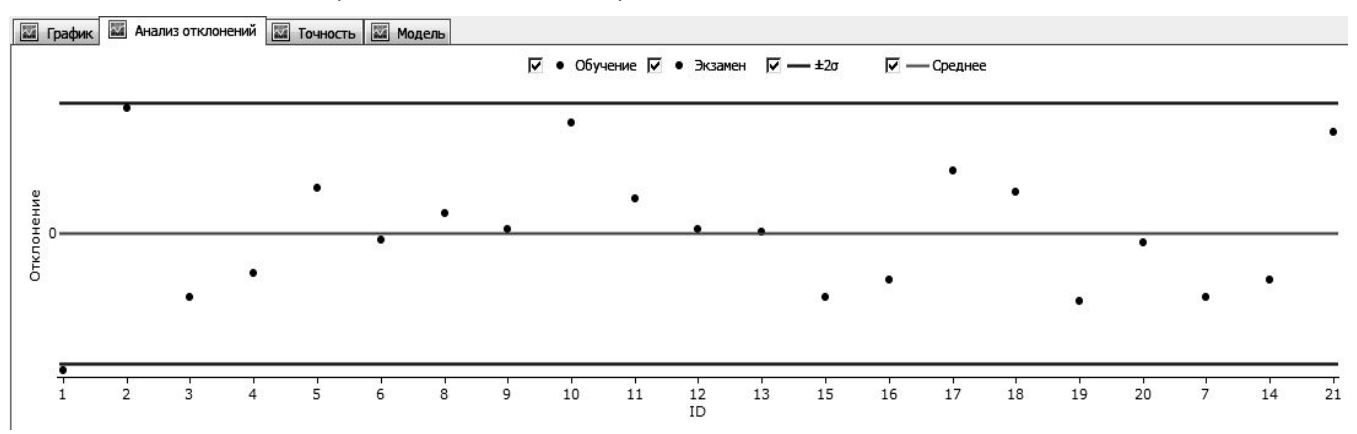

Рис. 2. Результати аналізу гетероскедастичності залишків моделі
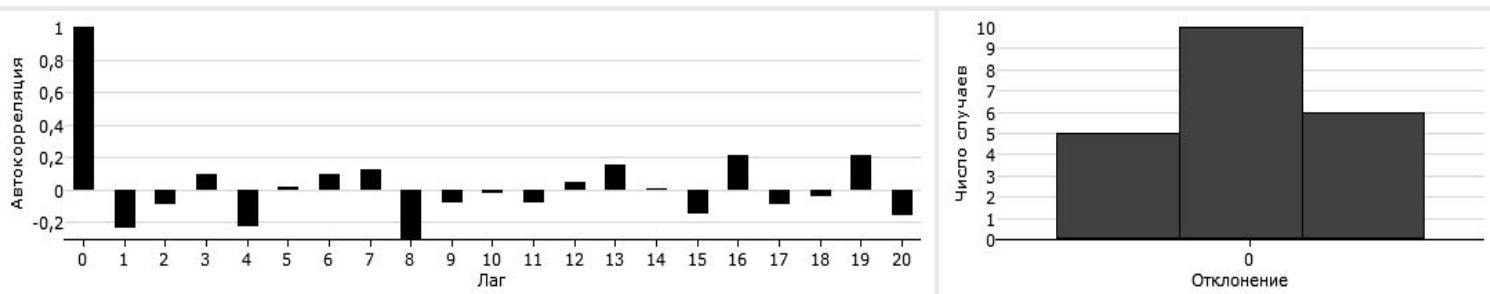

Рис 3. Результати аналізу автокореляції залишків моделі

На рис. 4 - характеристики достовірності отриманої моделі. Ключовою характеристикою достовірності моделі можна вважати коефіцієнт детермінації (R2), як долю дисперсії залежної змінної (якою $є$ інтегральна оцінка якості), що пояснюється отриманою моделлю. Близькість коефіцієнту детермінації до $1 \epsilon$ переконливим аргументом на користь якості отриманої моделі, яка здатна «пояснити» 99, 8 \% випадків варіацій залежної змінної.

На рис. 5 приведені оцінки значимості кожної 3 незалежних змінних, що входять до отриманої моделі. Така оцінка достатньо важлива 3 точки зору подальшого застосування моделі, а саме Modern Information Technologies in the Sphere of Security and Defence № 3(36)/2019 ISSN2311-7249(Print)/ISSN2410-7336(Onfine) $\quad 137$ 
аналізу змін властивостей ПмК, що можуть відбутися внаслідок структурної перебудови або модифікації існуючих моделей комплексу.

\begin{tabular}{ll}
\hline Макс. отрицательное отклонение & $-0,0010127$ \\
\hline Макс. положительное отклонение & 0,000545693 \\
\hline Средний модуль ошибки (СМО) & 0,000423177 \\
\hline Среднеквадратическое отклонение (СКО) & 0,000543866 \\
\hline Сумма отклонений & $-1,11022 \mathrm{~F}-15$ \\
\hline Стандартное отклонение остатков & 0,000543866 \\
\hline Коэффициент детерминации ( ${ }^{2}$ ) & 0,998906 \\
\hline Корреляция & 0,999453 \\
\hline
\end{tabular}

Рис 4. Характеристики достовірності отриманої моделі

\begin{tabular}{|c|c|c|c|c|}
\hline \multicolumn{3}{|c|}{ № Если заместить средним значением Влияние на СКО } & \multirow[t]{2}{*}{ Графически } & \multirow{2}{*}{$\begin{array}{l}\text { СКО } \\
0,0123457\end{array}$} \\
\hline 1 & 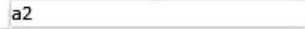 & $37,62 \%$ & & \\
\hline 2 & a1 & $36,15 \%$ & & 0,0118608 \\
\hline 3 & a3 & $35,36 \%$ & & 0,0116036 \\
\hline 4 & a4 & $31,91 \%$ & & 0,0104699 \\
\hline 5 & a5 & $31,63 \%$ & & 0,0103796 \\
\hline & [Ничего не замещено] & $0 \%$ & & $3,19485 E-13$ \\
\hline & [Замещено всё] & $100 \%$ & & 0,0328132 \\
\hline
\end{tabular}

Рис 5. Результати оцінки значимості незалежних змінних

Приведені на рис. 5 значення свідчать про правильне ранжування «внеску» незалежних змінних (обраних експертами властивостей) у інтегральну оцінку якості ПмК.

На рис. 6 показана графічна візуалізація залежності інтегральної оцінки від двох найбільш значущих незалежних змінних моделі адаптивності та адекватності полімодельного комплексу.

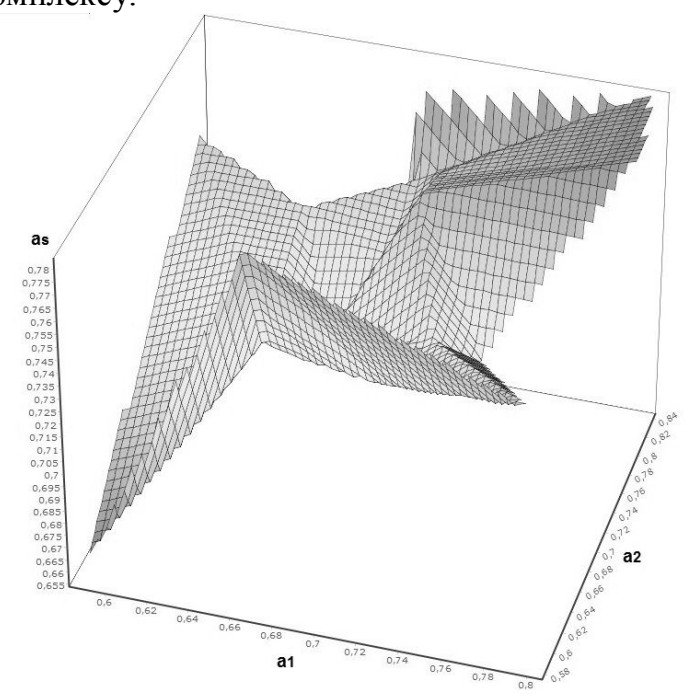

Рис. 6. Графічна залежність інтегральної оцінки від значущих змінних моделі оцінки якості

Отримана модель оцінки якості ПмК операцій (бойових дій) представляється у вигляді нелінійного поліному так, як показано на рис. 7.

За сукупністю проаналізованих характеристик отримана модель представляється цілком придатною для оцінювання якості полімодельного комплексу операцій (бойових дій) і може бути задіяна в якості інструменту вирішення двох загальних задач кваліметрії моделей - прямої (безпосереднє чисельне оцінювання якості), та зворотної - управління якістю моделей та комплексів


Рис. 7. Модель оцінки якості властивостей ПмК операцій (бойових дій)

Відносно оберненої задачі $\epsilon$ необхідними декілька зауважень. Управління якістю у даному випадку передбачає придання властивостей моделі (комплексу) із заданим рівнем якості i цілком залежатиме від мети, яку намагаються досягти розробники. Так, модифікація моделей (ПмК) має за мету, як правило, їх удосконалення за результатами дослідної експлуатації, і у більшості випадків призводить до підвищення однієї або декількох якісних оцінок певних властивостей (наприклад - простоти для користувача та адаптивності). У разі структурних змін ПмК (включення до їх складу нових моделей, задач, алгоритмів тощо) ситуація дещо складніша, оскільки підвищення якості одних властивостей може призвести до погіршення якості інших (наприклад - якщо включення нових моделей до складу ПмК спрямоване на підвищення достовірності отриманих результатів, це може призвести до ускладнення процесу користування комплексом моделей). В такому випадку доцільніше вести мову не стільки про підвищення якісних властивостей, скільки про збереження на необхідному рівні загальної (інтегральної) оцінки якості комплексу або моделі. Ще однією особливістю управління якістю моделей (ПмК) операцій можна вважати структурну реконфігурацію комплексів моделей, яка здійснюється з метою вибору такої моделі (задачі, алгоритму) з числа наявних, що у найбільший мірі відповідає поточному завданню та умовам моделювання. Така реконфігурація здійснюється

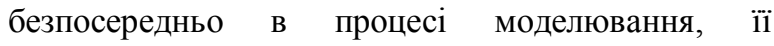
можливість визначається такою властивістю як адаптивність комплексу (моделі). Розгляд завдання управління якістю у такій постановці виходить за межі тематики статті і приводиться лише 3 метою окреслення напрямків вирішення зворотної задачі кваліметрії. 
У будь-якому випадку наявність інструменту для оцінювання якості типових властивостей моделей та ПмК операцій (бойових дій) надасть можливість обгрунтовано (з точки зору кваліметрії) підходити до модифікації та структурних змін у моделях та комплексах моделей операцій.

\section{Висновки й перспективи подальших досліджень}

Оцінка якісних характеристик моделей та ПмК операцій (бойових дій), як дієвого та необхідного інструменту роботи органів військового управління, є відповідальним етапом, за яким визначається ступінь придатності моделей до використання за призначенням. Кваліметрія моделей (чисельна оцінка якісних характеристик) передбачає необхідність урахування як об'єктивних властивостей, так і суб'єктивних оцінок корисності моделей (комплексів моделей), які кваліметрічними методами оцінюються одним узагальненим показником (інтегральним

\section{Лimepamypa}

1. Микони С.B. Квалиметрия моделей и полимодельных комплексов: монографія / С.В. Микони, Б.В. Соколов, Р.М. Юсупов. - М.: РАН, 2018. - 314 с. 2. Пятак И.А. Метрология, стандартизация, сертификация и аккредитация. - Д.: ДНУ, 2012. - 26 с. 3. Соколов Б.В. Концептуальные и методические основы квалиметрии моделей и полимодельных комплексов / Б.В. Соколов, Р.М. Юсупов // Труды Санкт-Петербургского института информатики и автоматизации РАН. - Санкт-Петербург: СПИИРАН, 2004. - Вып. 2. Т. 1. - С.10-34. 4. Охтилев М. Ю. Комплексное моделирование сложных объектов: основные особенности и примеры практической показником якості). Поєднання розвиненого методичного апарату оброблення експертної інформації 3 можливостями сучасних засобів аналізу даних дозволяє побудувати модель, яка спроможна 3 достатньо високою точністю розраховувати інтегральний показник якості обраних властивостей моделей, а також може бути використана для кваліметричного аналізу можливих модифікацій та структурних змін у моделях (ПмК). Розглянутий у статті практичний приклад (3 використанням діючого полімодельного комплексу операцій та залученням експертів) побудови моделі оцінки якості ПмК підтвердив можливість та доцільність такого підходу.

Перспективою подальших досліджень вважається розгляд питань, пов'язаних $з$ оцінкою кваліметрічними методами структурної реконфігурації полімодельних комплексів операцій (бойових дій) в процесі їх застосування в умовах часових обмежень.

\title{
ПРИМЕНЕНИЕ МОДИФИЦИРОВАННЫХ УРАВНЕНИЙ ДИНАМИКИ СРЕДНИХ ДЛЯ ОПЕРАТИВНОГО ПРОГНОЗИРОВАНИЯ ХОДА И РЕЗУЛЬТАТОВ БОЕВЫХ ДЕЙСТВИЙ
}

\author{
Борис Леонидович Бутвин (доктор технических наук, профессор) \\ Александр Александрович Машкин (кандидат технических наук, с.н.с.) \\ Алексей Иванович Соломицкий (кандидат военных наук, с.н.с.)
}

\section{Центральный научно-иследовательский институт Вооруженных Сил Украины, Киев, Украина}

В статье рассматриваются особенности оценки качества моделей и полимодельных комплексов операчий (боевых действий). Такие модели являются действенным и необходимым инструментом проведения оперативных расчетов на мероприятиях оперативной подготовки, а процедуры оченки их качественных свойств - важным и ответственным этапом жизненного ицила. $B$ рамках теоретической квалиметрии различают прямые и обратные задачи оченки качества, в основе первой лежит непосредственное измерение качества, в основе второй задачи - управление качеством продукта с иелью придания ему необходимых свойств. Особенную актуальность обратная задача приобретает для полимодельных комплексов операций (боевых действий), которые изначально строятся с гибкой структурой, что предусматривает возможность включения в их состав новых моделей или модификаџию уже существующих. Поскольку понятие качества включает как объективные свойства, так и субъективные оценки полезности объекта, которые квалиметрическими методами оцениваются одним обобщенным показателем, естественным является привлечение к таким оценкам экспертов в предметной области. Разработанность аппарата обработки экспертной информации вкупе $c$ современными программными средствами анализа и обработки данных предоставляет возможность упорядочивания проиесса оиенки качества наиболее важных свойств моделей и полимодельных комплексов. Это возможно путем установления нелинейной аналитической 
зависимости, которая свяжет независимые переменные (обработанные оценки экспертов) с зависимой переменной, в роли которой выступает интегральная оценка качества моделей. Пример построения такой зависимости с высоким коэффициентом детерминации интегральной оценки качества, рассмотренный в статье, подтвердил целесообразность такого подхода. Наличие описанного инструмента оченки качества позволит с достаточно высокой точностью рассчитывать интегральный показатель качества выбранных свойств моделей, а также может быть использовано для квалиметрического анализа возможных модификаций и структурных изменений в моделях и полимодельных комплексах операций (боевых действий).

Ключевые слова: квалиметрия моделей; полимодельный комплекс операций; качественная оценка свойств.

\title{
APPLICATION OF MODIFIED EQUATIONS OF DYNAMICS OF AVERAGE FOR OPERATIONAL FORECASTING OF THE TURN AND RESULTS OF BATTLE ACTION
}

\author{
Borys Butvin (Doctor of Technical Sciences, Professor) \\ Olexander Mashkin (Candidate of Technical Sciences, Senior Researcher) \\ Olexii Solomitskii (Candidate of Military Sciences, Senior Researcher)
}

\section{Central Scientific Research Institute of the Armed Forces of Ukraine, Kyiv, Ukraine}

The article discusses the peculiarities of evaluation of quality of models and multimodel complexes of operations (combat actions). Such models are an effective and necessary tool for operational calculations at operational training activities, and procedures for assessing their qualitative properties are an important and responsible phase of the life cycle. In theoretical qualifiers the direct and reverse tasks of quality assessment are distinguished, the first is based on the direct quality measurement, the second is the quality management of the product to give it the necessary properties. The reverse task becomes especially relevant for multimodel complexes of operations (combat actions), which are initially built with a flexible structure, which includes the possibility of adding new models or modifying existing ones. Since the concept of quality includes both objective properties and subjective assessments of the utility of an object, which are evaluated by a single generic indicator with a qualifying method, it is natural to involve experts in the subject area in such assessments. The development of an expert information processing unit, together with modern software tools for data analysis and processing, provides an opportunity to organize the process of quality assessment of the most important properties of models and multimodel complexes. This is possible by establishing a non-linear analytical dependency that links independent variables (processed expert estimates) to a dependent variable, which is an integral quality assessment of models. The example of such a dependency with a high determinative factor of integrated quality assessment, as discussed in the article, confirmed the usefulness of such an approach. Having the described quality assessment tool will allow to calculate the integral quality indicator of selected model properties with a high accuracy, as well as can be used for qualifying analysis of possible modifications and structural changes in models and multimodel complexes of operations (combat actions).

Keywords: model qualification; polymodel complex of operations; qualitative assessment of properties.

\section{References}

1. Mikoni S.V., Sokolov B.V., Yusupov R.M. (2018), Qualimetry of the models and polymodel complexes: monograph. [Kvalimetriya modeley i polimodel'nykh kompleksov: monografiya], RAS, Moscow, 314 p. 2. Pyatak I.A. (2012), Metrology, standardization, certification and accreditation. [Metrologiya, standartizatsiya, sertifikatsiya i akkreditatsiya], DNU, Dnepropetrovsk, 26 p. 3. Sokolov B.V., Yusupov R.M. (2004), Conceptual and methodical bases of the model and polymodel complexes qualification metering. [Kontseptual'nyye i metodicheskiye osnovy kvalimetrii modeley i polimodel'nykh kompleksov], Proceedings of the Saint-Petersburg Institute of Informatics and Automation of the Russian Academy of Sciences, SPIIRAN, SaintPetersburg, Issue 2. T. 1. pp. 10-34. 4. Okhtilev M.Yu., Pavlov A.N., Plotnikov A.M., Potryasaev S.A., Sokolov B.V., Yusupov R.M. (2015), Complex modeling of complex objects: main features and examples of practical implementation. [Kompleksnoye modelirovaniye slozhnykh ob" yektov: osnovnyye osobennosti i primery prakticheskiy realizatsii], Simulation modeling: Theory and practice (IMMOD-2015): plenary reports of the 7th scientificpractical conf. on imitation modeling and its application in science and industry, NOVIM, Moscow, pp. 58-81. 5. Kulayichev A.P. (2002), Data analysis methods and tools in Windows environment. STADIA. [Metody $\mathrm{i}$ sredstva analiza dannykh $\mathrm{v}$ srede Windows. STADIA], Informatics and Computers, Moscow, $341 \mathrm{p}$. 6. Zagorka O.M., Mosov S.P., Sbitnev A.I., Stizhuk P.I. (2005), Elementary research of the complex military systems: textbook. [Elementy doslidzhennya skladnykh system viys'kovoho pryznachennya: posibnyk], NADU, Kiev, 72 p. 